Res Pública Revista de Historia de las Ideas Políticas

ISSN: 1131-558X

http://dx.doi.org/10.5209/rpub.68391

\title{
El poder de la polis. Notas sobre la crítica arendtiana de la filosofía política platónica*
}

\author{
Cristina Basili**
}

Recibido: 3 de febrero de 2019 / Aceptado: 18 noviembre de 2019

Resumen. Uno de los rasgos más innovadores del pensamiento de Hannah Arendt se halla en su original concepción del poder político. En oposición a la tradición filosófico-política occidental, la autora rescata una noción positiva de poder, como resultado de la acción colectiva, mientras que desvincula poder y violencia. Este artículo presenta un análisis del concepto arendtiano de poder y una reconstrucción detallada de su génesis en el pensamiento de Arendt. En particular, se examina el vinculo entre la elaboración alrededor del poder, la crítica de la filosofía platónica y la interpretación del mundo griego clásico. De esta manera, se procura demostrar como la polis representa, en la obra arendtiana, un laboratorio conceptual para la renovación las categorías políticas modernas.

Palabras clave: Arendt; poder; violencia; Grecia; polis; Platón.

\section{[en] The Power of the Polis. Remarks on Arendt's Critique of Plato's Political Philosophy}

Abstract. One of the most innovative traits of Hannah Arendt's thought is her original conception of political power. In opposition to the Western philosophical-political tradition, the author develops a positive notion of power, as the result of collective action, while she dissociates power from violence. This article aims to present an analysis of the Arendtian concept of power and a detailed reconstruction of its genesis. In particular, I will examine the link between the elaboration of the concept of power, the critique of Plato's Political Philosophy and the interpretation of the classical Greek world. In this way, I will demonstrate how the polis works in her thought as a conceptual laboratory for the renewal of the modern political categories.

Keywords: Arendt; Power; Violence; Greece; Polis; Plato.

Sumario. 1. El poder que nos une. 2. El filósofo y la caverna. 3. El tesoro perdido.

Cómo citar: Basili, C. (2020). El poder de la polis. Notas sobre la crítica arendtiana de la filosofía política platónica. Res Pública. Revista de Historia de las Ideas Políticas, 23(1), 57-65.

En 1969 Hannah Arendt publica un ensayo titulado Sobre la violencia ${ }^{3}$. En el texto, a partir de la crítica de la exaltación de la violencia como herramienta de lucha política, promovida por los movimientos sociales de la época y sus teóricos, la autora llega a redefinir algunos conceptos clave del pensamiento político. Entre ellos, Arendt formula una noción de poder que se opone a esa tradición que, concibiendo el mismo como medio para un fin, lo asimila al reino de la autoridad, de la violencia y de la fuerza. Frente a esta confusión, que echa sus raíces en el carácter instrumental de la teoría política moderna, la pensadora propone una idea de poder alternativa al considerarlo como fin en sí mismo, fenómeno que surge de forma espontánea en el momento en que los hombres se reúnen y actúan en conjunto. A la tradicional división vertical y jerárquica entre los que mandan y los que obedecen, la pensadora opone una visión radicalmente horizontal de la energía que se desprende de la acción política colectiva. Esta operación se relaciona con la voluntad, por parte de Arendt, de redefinir los confines del espacio público, más allá de las estructuras categoriales propias del Estado-nación. En este intento de desconectar la idea de poder de la idea de dominio, la labor de decons-

\footnotetext{
El presente trabajo ha sido llevado a cabo gracias a la obtención de una Ayuda Juan de la Cierva-formación (2017) concedida por el Ministerio de Ciencia, Innovación y Universidades y la consecuente incorporación en el Grupo de investigación "Historia y ontología del presente: la perspectiva hispana" de la Universidad Complutense de Madrid, dirigido por el Prof. José Luis Villacañas. Agradezco a Víctor Caleya su atenta revisión del texto.

** Universidad Complutense de Madrid

cri.basili@gmail.com

H. Arendt, Sobre la violencia, Madrid, Alianza, 2005.
} 
trucción de la tradición filosófico-política occidental desempeña un papel fundamental. En concreto, la referencia a "otra tradición", que encontramos en el capítulo dedicado a la reconfiguración de la noción de poder, permite vincular el discurso arendtiano con la relación crítica que éste entretiene no solamente con algunos pensadores modernos, sino con el mundo antiguo griego-romano ${ }^{2}$. Desde este punto de vista es posible afirmar que el análisis sobre el sentido de la experiencia de la polis, que Arendt lleva a cabo en escritos anteriores, funciona como laboratorio de búsqueda de herramientas conceptuales capaces de reactivar el carácter inmanente de una política entendida como ejercicio de libertad entre iguales ${ }^{3}$.

La reconstrucción de las etapas intelectuales que vinculan las reflexiones sobre el poder a las elaboraciones sobre la Grecia clásica permite desarrollar no solamente una perspectiva crítica sobre las mismas, sino destacar aquellos rasgos del pensamiento arendtiano en condiciones de captar tanto la crisis como las exigencias de renovación propias de la teoría política contemporánea. Apuntando a la tensión entre los términos filosofía y política, la autora pretende llevar a cabo una deconstrucción de la visión tradicional de la relación entre teoría y praxis a la vez que desprende de ella la necesidad de operar en dirección de una politización de la teoría ${ }^{4}$. Si la política se relaciona con la pluralidad de los hombres y su necesidad de actuar conjuntamente en la organización del espacio público, la teoría indica la contemplación solitaria de la experiencia. La expresión "teoría política" representa así un oxímoron del que procede una determinada visión de los asuntos humanos. De este argumento Arendt deriva la necesidad de cuestionar la forma tradicional de concebir la teoría política, poniendo la atención en el momento originario, platónico, que la inaugura ${ }^{5}$.

Se vuelve relevante, por tanto, para la autora, una recuperación crítica del pensamiento platónico que discierna tanto los procesos de neutralización implicados en el planteamiento epistémico de la filosofía como el papel que esta desempeña en relación con la esfera política ${ }^{6}$. La lectura arendtiana de los diálogos de Platón se centra en la tensión trágica entre la reductio ad unum propia de la filosofía y la inabarcable variedad de la experiencia político-social. Esta lectura pretende interrogarse, tras los catastróficos acontecimientos del siglo $\mathrm{xx}$, tanto acerca de las potencialidades de la teoría, más allá de sus límites tradicionales, como sobre la esencia de la política, más allá de una visión que

\footnotetext{
H. Arendt, op. cit., p. 55.

Para un análisis más detenido de este aspecto de la concepción arendtiana de la polis clásica, me permito reenviar a mi ensayo: C. Basili, "Los límites de la política. Hannah Arendt sobre la polís clásica" en M. Alviz Fernández, D. Hernández de la Fuente, De horos a limes: el concepto de frontera en el mundo antiguo y su recepción, Madrid, Escolar y Mayo Editores, 2017, pp. 241-252.

4 Sobre este tema, cf. A. Cavarero, "Politicinzg theory", en Political Theory, 4, 2002, pp. 506-532.

5 Sobre la relevancia de la cuestión de la vuelta al origen en el pensamiento contemporáneo, cf. G. Cambiano, Il ritorno degli antichi, Roma-Bari, Laterza, 1988, en particular, las páginas dedicadas a Martin Heidegger, pp. 20-24. El problema del origen en Arendt ha sido tratado en R. Esposito, El origen de la política. ¿Hannah Arendt o Simone Weil?, Barcelona, Paidós, 1999.

6 Sobre estos aspectos de la filosofía platónica, cf. M. Vegetti, Los origines de la racionalidad cientifica: el escalpelo y la pluma, Barcelona, Península, 1981, pp. 91-106.
}

vincula la misma a un dispositivo de gobierno del conflicto. La pensadora detecta, en otros términos, no solamente la brecha entre política y filosofía, sino que asume esta divergencia como esencial a la estructura categorial de la teoría misma, tal como esta se ha venido configurando desde Platón en adelante. No se trata, por tanto, de pensar lo inadecuado de una filosofía política dada, sino de determinar el vínculo que en cuanto tal la filosofía política, y la tradición que la hereda, entabla con su proprio objeto. Esta operación implica señalar una relación directa entre la forma de la filosofía política y su incapacidad de comprender la política. La pretensión de la filosofía de fundar la política vincula su horizonte categorial a la representación de un orden que procura neutralizar la realidad fáctica de la política misma?

Se trata, por tanto, para Arendt, de desarrollar una reflexión acerca de la política, reconfigurando el termino a partir de las estratificaciones de sentido que se encierran en la palabra misma ${ }^{8}$. Desde esta perspectiva, los análisis arendtianos no contienen solamente una crítica radical de las categorías modernas de la política ${ }^{9}$, sino que invitan además a la elaboración de una teoría política en condiciones de captar fenomenológicamente las instancias determinadas por su contacto con la realidad. De esta manera, la autora logra tanto una ampliación de la vertiente crítica de la teoría política como de su capacidad de imaginar escenarios alternativos, a la altura de los desafíos que se imponen al pensamiento político contemporáneo $^{10}$. La perspectiva arendtiana lleva a reconsiderar una teoría política libre de la gramática del orden en la medida en que encierra una serie de intuiciones que apuntan a desarticular las abstracciones de la ontología tradicional, rescatando el léxico de la pluralidad, más allá de la violencia fundadora. En este cuestionamiento sobre los comienzos de la filosofía política, Arendt toma distancia con una tradición que tiende a negar la contingencia de la política y encuentra por este camino una concepción del poder alternativa, enfocada en la dimensión esencialmente relacional de la praxis ${ }^{11}$.

\section{El poder que nos une}

La idea arendtiana de poder se construye de forma gradual en la producción de la autora. En su obra más celebre, Los orígenes del totalitarismo, de 1951, Arendt se sirve todavía de una noción convencional de poder político, asociando dicho término al uso de la violencia ${ }^{12}$. Sin embargo, a partir de los años inmediatamente sucesivos, su reflexión puede

Roberto Esposito aborda en estos términos el problema de las relaciones entre filosofía y política en: R. Esposito, Diez pensamientos acerca de la política, Buenos Aires, Fondo de Cultura Económica, 2012, pp. 33-39.

Cf. a este respecto, las anotaciones presentes en L. Bazzicalupo, Hannah Arendt. La storia per la poltica, Napoli, Edizioni Scientifiche Italiane, 1996, pp. 18-31 y F. Birulés, "Introducción. ¿Por qué debe haber alguien y no nadie?”, en H. Arendt, ¿Qué es política?, Barcelona, Paídos, 1997, pp. 9-41, aquí pp. 11-12.

9 Sobre este tema, cf. G. Duso, Il potere: per la storia della filosofia politica moderna, Roma, Carocci, 1999, pp. 429-436.

10 Cf. A. Cavarero, op. cit., pp. 515-530.

11 Cf. a este respecto, O. Guaraldo, "Postcritica: una genealogia", en Politica\&Società 2, 2018, pp. 163-190.

12 H. Arendt, Los orígenes del totalitarismo, Madrid, Alianza, 2006. 
interpretarse como el esfuerzo constante de separar y distinguir ambos términos ${ }^{13}$. Este intento toma consistencia a partir de un texto de 1953, titulado Karl Marx y la tradición del pensamiento político occidental ${ }^{14}$, donde se observa el germen de una reflexión que intenta desvincularse de la manera tradicional de concebir el poder político. A partir del antiguo significado de nomos, Arendt elabora una idea de ley entendida como confín que conserva y protege en su interior el espacio político que se forma a partir de las acciones de los ciudadanos:

En este modo distinto de considerar la ley saldría a la luz un concepto de poder totalmente diverso, cuyo significado está contenido en la raíz etimológica del termino mismo. Power, pouvoir, posse o dynamis significan potencialidad y se distinguen por tanto de la potencia, cualquier cosa que está a mi completa disposición, que de verdad es posesión mía. En este significado, el poder se hace posible, llega a ser, sólo porque y sólo cuando el individuo comienza a actuar. Y el actuar, en cuanto distinto del hacer, implica siempre una relación con otros [...] Potencia, habilidad y violencia residen en mí mismo y están a mi disposición, el poder requiere la pluralidad de los hombres. Porque el poder no es cualquier cosa que yo posea por naturaleza; llega a ser, no en los hombres, sino entre los hombres cada vez que estos actúan juntos y de común acuerdo. Llega a ser, por ejemplo, durante la fundación de una comunidad ${ }^{15}$.

A partir de estas citas, se pueden subrayar tres directrices que se convertirán en características de la concepción arendtiana. En primer lugar, el carácter contingente, potencial y plural del poder, de cara a una tradición que lo ha pensado como una relación vertical, creadora de orden. En segundo lugar, su desvinculación de la dinámica de la potencia, cuya connotación instrumental se relaciona con un elemento intrínseco de violencia. En tercer lugar, la espacialización del poder, el cual sólo puede ser efecto de determinadas relaciones, propiamente políticas, entre los hombres $^{16}$. De esta manera, el poder representa una de las manifestaciones de la política, mientras que esta última surge solamente allí donde los hombres actúan juntos, es decir, donde crean una comunidad, una polis, compartiendo un mundo en común. La política es creadora, según Arendt, de un espacio público virtual-siempre posible en potencia y, a la vez, siempre en peligro de desaparecervehiculado por la potencialidad misma del poder y amenazado por la precariedad intrínseca a los asuntos humanos. El poder así concebido no se caracteriza por ser una herramienta de coacción y estabilidad, no se relaciona con

13 Cf. S. Forti, Vida del espíritu y tiempo de la polis. Hannah Arendt entre filosofía y política, Madrid, Cátedra, 2001, p. 363.

14 Una versión de este trabajo ha sido publicada en: H. Arendt, Karl Marx y la tradición del pensamiento político occidental, Madrid, Encuentro, 2007.

15 Estas anotaciones se encuentran en: H. Arendt, Karl Marx and the Tradition of Western Political Thought, long draft, 1953, Washington, Library of Congress, Manuscripts Division, "The papers of Hannah Arendt", box 64, respectivamente pp. 44 y 46. El acceso a los manuscritos digitalizados está disponible en la siguiente URL: https://memory.loc.gov/ammem/arendthtml/arendthome.html. Se ha utilizado la traducción castellana de los pasajes mencionados presente en S. Forti, op.cit., p. 364.

16 Sobre la espacialización de los conceptos políticos en Arendt, cf.: L. Bazzicalupo, op. cit., pp. 18-25. el Estado y la violencia o, mejor dicho, con el monopolio de ésta por parte del Estado, sino que estrecha un vínculo con la esencia de lo político, surgiendo de ello como efecto de la condición plural de los hombres y de su capacidad de actuar juntos. Pensando el poder contra la dominación -pensando el poder como aquella realidad que se resiste a la dominación de los hombres sobre los hombres-Arendt lo considera, más allá de sus manifestaciones concretas, en su forma pura. Reconocer el poder significa, para ella, reconocer uno de los rasgos auténticos de la experiencia política, ocultados por la tradición dominante, a la vez que implica el desarrollo de una concepción alternativa que apunta a otros horizontes prácticos y especulativos ${ }^{17}$.

Estas son las directivas que la pensadora vuelve a proponer en sus obras posteriores, La condición humana $(1958)^{18}$ y Sobre la revolución (1963) ${ }^{19}$, y que finalmente sistematiza en el ensayo Sobre la violencia de $1969^{20}$. Arendt es, en aquel entonces, profesora en la New School for Social Research de Nueva York. El texto se sitúa en la época de las revueltas estudiantiles y responde, por tanto, a una coyuntura caracterizada, por una parte, por la tentación del recurso a la violencia dentro de la nueva izquierda estadounidense, por otra, por el uso de la violencia por parte de las autoridades universitarias mismas. En el trasfondo, la guerra de Vietnam y la Guerra Fría, con su amenaza de un conflicto nuclear. Además, la polémica de Arendt se centra en la exaltación de la violencia entendida como herramienta revolucionaria, productora de poder político, presente en un texto que tuvo gran repercusión en la época, Los condenados de la tierra de Frantz Fanon, publicado en Francia en 1961 con una introducción de Jean-Paul Sartre ${ }^{21}$. Seguramente Arendt está refiriéndose a ese contexto cuando escribe: "La violencia puede siempre destruir al poder; del cañón de un arma brotan las órdenes más eficaces que determinan la más instantánea y perfecta obediencia. Lo que nunca podrá brotar de ahí es el poder"22. Sin embargo, añade:

políticamente hablando, es insuficiente decir que poder y violencia no son la misma cosa. El poder y la violencia son opuestos; donde uno domina absolutamente falta el otro. La violencia aparece donde el poder está en peligro pero, confiada a su propio impulso, acaba por hacer desaparecer al poder. Esto implica que no es correcto pensar que lo opuesto de la violencia es la no violencia; hablar de un poder no violento constituye en realidad una redundancia. La violencia puede destruir al poder; es absolutamente incapaz de crearlo ${ }^{23}$.

Con estas palabras la pensadora amplía su marco polémico y deja de dirigirse solamente a los activistas

\footnotetext{
Cf. O. Guaraldo, op. cit., p. 178.

18 H. Arendt, La condición humana, Barcelona, Paidós, 1998.

H. Arendt, Sobre la revolución, Madrid, Alianza, 2004.

H. Arendt, Sobre la violencia, op.cit.

21 F. Fanon, Los condenados de la tierra, Tafalla, Txalaparta, 2011. Para una comparación entre Arendt y Fanon sobre el tema de la violencia, cf.: Á. Prior Olmos, "El debate sobre la violencia: Arendt y Fanon”, en J.L. Villacañas Berlanga y C. Ruiz Sanjuán (eds.), Populismo versus Republicanismo. Genealogía, historia, crítica, Madrid, Biblioteca Nueva, pp. 131-150.

22 H. Arendt, Sobre la violencia, op.cit., p. 73.

$23 \quad$ Ibidem, p. 77.
} 
para referirse a la teoría política en su conjunto, a su terminología, a su incapacidad de distinguir entre fenómenos distintos. La importancia de esta tarea de distinción, separación y aclaración de conceptos es, en Arendt, un recurso que se encuentra en muchas de sus obras: no se trata solamente de un método de investigación, sino también de una exigencia intelectual, de una respuesta a la falta de pensamiento que atraviesa el mundo contemporáneo y, en un nivel más profundo, al intento fenomenológico de iluminar el estrato olvidado de la vida en común, de su modalidad de existencia y de las condiciones de su apariencia ${ }^{24}$. Con este fin, la autora tiene la pretensión de desmantelar una tradición de pensamiento que ha llevado a esas confusiones que convierten en opacos los términos de las relaciones políticas. A lo largo de los siglos, el poder siempre ha sido pensado en términos de dominación. Distinguir el poder de la dominación implica, por tanto, evitar el error de reducir la teoría política a la cuestión del gobierno:

Tras la aparente confusión existe una firme convicción a cuya luz todas las distinciones serían, en el mejor de los casos, de importancia menor: la convicción de que la más crucial cuestión política es, y ha sido siempre, la de ¿Quién manda a Quién? Poder, potencia, fuerza, autoridad y violencia no serían más que palabras para indicar los medios por los que el hombre domina al hombre; se emplean como sinónimos porque poseen la misma función. Sólo después de que se deja de reducir los asuntos públicos al tema del dominio, aparecerán o, más bien, reaparecerán en su auténtica diversidad los datos originales en el terreno de los asuntos humanos ${ }^{25}$.

Esta postura no conlleva una falta de realismo por parte de Arendt; ella misma considera que, en la realidad de los hechos, "nada resulta tan corriente como la combinación de violencia y poder, y nada es menos frecuente como hallarlos en su forma pura y por eso extrema"26, pero no se deduce de ello que la autoridad, la fuerza, el poder, la potencia y la violencia sean todos ellos lo mismo. El poder corresponde "a la capacidad humana, no simplemente para actuar, sino para actuar concertadamente. El poder nunca es propiedad de un individuo; pertenece a un grupo y sigue existiendo mientras que el grupo se mantenga unido"27. En otras palabras, el poder se basa en la acción concertada y no tiene existencia fuera de ella; no implica en ningún momento la sumisión, sino que se halla en la cohesión de un espacio público; es un fenómeno colectivo que surge a partir de la comunicación entre iguales que deciden actuar juntos. Su dimensión no es ni exterior al cuerpo social, ni está interiorizada en el hombre, sino que se halla en la dimensión plural del inter-esse, creadora y organizadora de una comunidad política, y no tiene otro fin que no sea su propia existencia ${ }^{28}$. Frente al carácter instrumental de

\footnotetext{
24 Cf. P. Ricoeur, "Pouvoir et violence" en M. Abensour (ed.), Ontologie et politique: Actes du Colloque Hannah Arendt, Paris, Tierce, pp. 148-149.

25 H. Arendt, Sobre la violencia, op.cit., p. 60

26 Ibidem, p. 64.

27 Ibidem, p. 60.

28 Cf. A. Enegrén, La pensée politique de Hannah Arendt, Presses Universitaires de France, Paris, 1984, p. 100.
}

la violencia, que es un medio para un fin, el poder representa un fin en sí mismo:

la estructura del poder en sí mismo precede y sobrevive a todos los objetos, de forma que el poder, lejos de constituir los medios para un fin, es realmente la verdadera condición que permite a un grupo de personas pensar y actuar en términos de categorías medios-fin. Y como el Gobierno es esencialmente poder organizado e institucionalizado, la pregunta: ¿cuál es el fin del Gobierno?, tampoco tiene mucho sentido. La respuesta será, o bien la que cabría dar por sentada -permitir a los hombres vivir juntos-o bien peligrosamente utópica - promover la felicidad, o realizar una sociedad sin clases o cualquier otro ideal no político, que si se examinara seriamente se advertiría que sólo podía conducir a algún tipo de tiranía ${ }^{29}$.

La identificación tradicional de poder y violencia hunde sus raíces no sólo en la realidad política, donde a menudo se encuentran mezclados, sino también, como se ha visto, en el hecho de que la política se ve tradicionalmente reducida a la cuestión del dominio del hombre sobre el hombre. Cabe interpretar la crítica de esta formulación como consecuencia teórica de la elaboración arendtiana en torno a la cuestión del totalitarismo ${ }^{30}$. Efectivamente la autora lee el fenómeno totalitario como un evento clave que marca una fractura en la historia de Occidente, obligando a una revisión de la tradición que ha llevado a la implosión de las modernas categorías de la política. Tanto el nacionalsocialismo como el estalinismo representan para Arendt fenómenos de despolitización, de neutralización del espacio público, en los que se opera una inversión fundamental entre medios y fines: frente a una política entendida como relación vertical de mando y obediencia, Arendt rehabilita la autonomía de lo político, el carácter no instrumental de una acción plural que obtiene su justificación exclusivamente de sí misma ${ }^{31}$. Desde este punto de vista, una correcta comprensión de los análisis arendtianos alrededor del problema del poder, implica un estudio de sus estrategias argumentativas. Por parte de los intérpretes, se ha destacado el carácter limitado de una reflexión sobre la cuestión del poder que no tenga en cuenta la dimensión social del mismo, aislando la reflexión política de las condiciones concretas y materiales en la que se encarnan las lógicas del dominio ${ }^{32}$.

Sin embargo, el corte crítico y analítico de las reflexiones arendtianas, que aísla al poder como fenómeno puro respecto a sus interacciones con otros componentes, no tiene como fin la propuesta de un escenario político idealizado con rasgos utópicos o normativos ${ }^{33}$, más bien, señala que, en el momento en el que poder y violencia se confunden, lo que se está produciendo es una

H. Arendt, Sobre la violencia, op.cit., p. 71.

30 Cf. H. Brunkhorst, "The Productivity of Power: Hannah Arendt's Renewal of the Classical Concepts of Politics", Revista de ciencia politica 2, 2006, p. 125.

31 Cf. S. Forti, Totalitarismo. Trayectoria de una idea limite, Barcelona, Herder Editorial, 2008, p. 178.

32 Cf. J. Habermas, "Hannah Arendt's Communications Concept of Power", Social Research 44, 1977, pp. 3-24.

33 Cf. A. Dal Lago, "La città perduta", en H. Arendt, Vita activa. La condizione umana, Bompiani, Milano, 2006, pp. VII-XXXIII. 
perversión de la vida social ${ }^{34}$. Frente a las dinámicas potencialmente totalitarias implícitas en la configuración del gobierno, Arendt lleva a cabo una inversión que no la conduce a la búsqueda de un modelo político alternativo, sino de aquellos momentos históricos privilegiados en los que la política ha sido capaz de asumir otro significado; de ahí su interés por la polis clásica, la Revolución americana, la Comuna de París o la experiencia de los Soviet ${ }^{35}$. Sería desde este punto de vista posible valorizar la pars construens de un pensamiento que pone en campo la productividad de la teoría a la hora de pensar la vida política en términos positivos, generativos y relacionales $^{36}$. En Arendt no encontramos, por tanto, una idealización del mundo griego, sino una reflexión atenta sobre la auto-representación de este mismo que nos devuelve un imaginario en condiciones de contrastar el paradigma político dominante en la contemporaneidad. En este sentido se vuelve relevante para Arendt desarrollar un análisis detenido de las fuentes, con el fin de proceder a una deconstrucción de la tradición filosóficopolítica occidental. Es en este contexto que la crítica a la filosofía política platónica se configura como un pasaje obligado para discernir aquellos procesos que, en el seno mismo de la polis, llevan a la elaboración de una forma de pensamiento que quiere imponerse frente a la realidad fáctica de la existencia política.

\section{El filósofo y la caverna}

Tal como se ha destacado anteriormente, la referencia crítica de Arendt es la tradición de la filosofía política occidental, en la peculiar acepción que la definición de filosofía política asume para ella. Filosofía política es, para Arendt, un sistema de pensamiento en el cual el término "política" ha sido sometido por la violencia teórica de las categorías filosóficas. El carácter contingente, plural y potencial de la política se pierde en el momento en que se produce una separación entre teoría y praxis y donde esta última queda descalificada por la superioridad concedida a la primera. De esta manera, la vida contemplativa asume prioridad ontológica respecto a la vida activa, produciendo una inversión que permanece como gesto fundador de una tradición de pensamiento:

Nuestra tradición de pensamiento político tuvo su comienzo definido en las enseñanzas de Platón y Aristóteles. Creo que llegó a un fin no menos definido en las teorías de Karl Marx. El comienzo se produjo cuando, con la alegoría de la caverna, Platón describió en la República la esfera de los asuntos humanos -todo lo que pertenece a la coexistencia de los hombres en un mundo común- en términos de oscuridad, confusión y decepción, de las que quienes aspiran al ser verdadero deben apartarse y dejarlas atrás, si quieren descubrir el firmamento límpido de las ideas eternas [...] La filosofía política necesariamente implica la actitud del

34 Cf. R. Bernstein, Violence. Thinking without banisters, Malden, Polity Press, 2006, pp. 86-87.

35 Cf. C. Lefort, "Hannah Arendt and the Question of the Political", en ibidem, Democracy and Political Theory, Minneapolis, University of Minnesota Press, 1988, p. 50.

36 Cf. O. Guaraldo, op. cit., p. 177-180. filósofo ante la política; su tradición comenzó cuando el filósofo se apartó de la política y después regresó a ella para imponer sus normas en los asuntos humanos. El fin se produjo cuando un filósofo se apartó de la filosofía como para "llevarla adelante" en el campo político ${ }^{37}$.

Estas afirmaciones reclaman un análisis de la interpretación arendtiana del pensamiento platónico con el fin de entender no solamente las inversiones que allí se operan, sino también las experiencias que este intentan dejar atrás, superándolas en el sentido de una organización racional de la vida pública conforme a los principios derivados de la propia filosofía. Arendt aborda la filosofía de Platón a partir de una mirada que deja en segundo plano las cuestiones estrictamente filológicas en favor de una lectura centrada en los problemas heredados por la tradición. Su objetivo es aquel de criticar una interrelación entre teoría y praxis que, a su modo de entender, sigue invariada incluso en la configuración marxiana que somete la filosofía a las directivas de la política $^{38}$. De tal manera es posible, para Arendt, afirmar que: "nuestra tradición de filosofía política, desgraciada y fatalmente, y desde su comienzo, ha privado de toda dignidad suya propia a los asuntos políticos, eso es, a aquellas actividades concernientes al espacio público común que viene a existir dondequiera que los hombres viven juntos" 39 y que, en consecuencia, "la filosofía política nunca se recuperó de este golpe asestado por la filosofía a la política en el comienzo mismo de nuestra tradición"

Este enfoque revela la influencia sobre Arendt de la lectura heideggeriana de la filosofía platónica. Para ambos pensadores, la interpretación del pensamiento de Platón entraña mucho más que un simple juicio sobre el filósofo griego, sino que predetermina la actitud respecto a toda la tradición filosófica ${ }^{41}$. Esta aproximación teórica le permite a Arendt trasladar a su interpretación de la tradición occidental la teoría heideggeriana de que la Idea, como herramienta filosófica, es en sí una forma técnica de dominio. Platón es, por lo tanto, el prototipo de la filosofía abstracta e instrumental. Para sustentar este tipo de interpretación, la pensadora propone una lectura de la filosofía platónica que otorga relevancia a la representación de la tensión entre filosofía y política, tal como la que se derivaría de la República y, en particular, del mito de la caverna. En el mito, se expli-

\footnotetext{
H. Arendt, Entre el pasado y el futuro. Ocho ejercicios sobre la reflexión política, Péninsula, Barcelona, 2003, pp. 33-34.

38 Sobre la crítica a Marx, cf. H. Arendt, Karl Marx y la tradición del pensamiento político occidental, op. cit., pp. 65-66.

9 Ibidem, p. 61.

${ }^{41}$ Cf. S. Forti, Vida del espíritu y tiempo de la polis. Hannah Arendt entre filosofia y política, op.cit., p. 137-138. Sobre la forma en la que Arendt reelabora en clave crítica el legado de Heidegger en relación con el tema de la tensión entre ontología y política, cf. J. Álvarez Yágüez, "Polís y política: M. Heidegger y H. Arendt", Res Publica 22, 2019, pp. 195-215. Sobre la relación entre el pensamiento de Arendt y Heidegger, cf. también J. Taminiaux, "Arendt, disciple de Heidegger?”, Etudes phénoménologiques 2, 1985, pp. 111-136; M. Canovan, "Socrates or Heidegger? Hannah Arendt's Reflections on Philosophy and Politics", Social Research 1, 1990, pp. 135-165; B. Cassin, "Grecs et Romains: les paradigmes de l'antiquité chez Arendt et Heidegger”, en M. Abensour (ed.), op.cit., pp. 17-39.
}

$40 \quad$ Ibidem, p. 63. 
citaría el elemento anti-político presente en la idea del poder de los filósofos, la cual engendra la primera forma de "tiranía de la verdad"42. Ese poder de los filósofos "sobre" la ciudad sería, para Arendt, todo lo contrario del poder que surge "en" la ciudad, que representaría, en cambio, la dimensión auténtica de la política ${ }^{43}$. Siguiendo la reconstrucción arendtiana, esta exigencia de dominio se manifestaría en Platón como respuesta a la situación histórica que determina el proceso a Sócrates y que termina en la condena a muerte del filósofo. Ante esta situación de persecución y precariedad, la doctrina de las Ideas, una doctrina en principio exclusivamente filosófica, sería reconvertida con fines políticos a la hora de defender a los filósofos de la amenaza representada por la vida de la polis ${ }^{44}$.

La separación entre "filosofo" y "ciudadano" sería representativa, a un nivel más profundo, de la disgregación de esa concepción unitaria del logos por la cual la racionalidad del hombre no podía separarse de su politicidad. La solución ofrecida por Platón intenta establecer, por primera vez en la historia, un fin exterior a la política misma que no sea el poder común que surge del hecho, para los hombres, de vivir juntos. El problema del filósofo ateniense sería el de encontrar una forma para reducir los hombres a la obediencia, sin recurrir a la fuerza. De allí, que las Ideas como verdades evidentes se vuelvan instrumentos de poder: "esas ideas se pueden usar como medida del comportamiento humano, porque trascienden de la esfera de los asuntos humanos del mismo modo en que una vara de determinada longitud trasciende, está fuera y por encima de todas las cosas cuya longitud puede medir" 45 . Por ser esta concepción ajena a la vida política tal como la entendían los griegos, Platón tiene que recurrir a una serie de ejemplos extrapolados de la esfera privada, como la relación entre el amo y el esclavo, el pastor y su rebaño, el médico y el paciente. Destaca a tal propósito Arendt:

En todos estos ejemplos, el conocimiento del experto suscita confianza, de modo que o bien ni la fuerza ni la persuasión son necesarias para conseguir el acatamiento, o bien el gobernante y el gobernado pertenecen a dos categorías de seres muy distintas, una de las cuales ya está sometida a la otra de modo implícito ${ }^{46}$.

Es así como, en Platón, "saber lo que hay que hacer y hacerlo se convierten en funciones separadas y mutuamente excluyentes" ${ }^{47}$. Lo que Platón buscaba, en otras palabras, era "una relación en la que el elemento compulsivo está en la relación misma y es anterior a la formulación especifica de los órdenes"48. Lo relevante para Arendt es que el pensamiento de Platón se va formando

42 H. Arendt, "Sócrates", en H. Arendt, La promesa de la política, Barcelona, Paidós, 2008, pp. 43-45, aquí p. 49.

43 Sobre la interpretación arendtiana del mito de la caverna, cf. M. Abensour, "Against the Sovereignity of Philosophy over Politcs: Arendt's Reading of Plato's Cave Allegory", Social Research 74, 2007, pp. 985-992 y A. Cavarero, "Note arendtiane sulla caverna di Platone", en S. Forti, Hannah Arendt, Milano, Bruno Mondadori Editore, 1991, pp. 205-225.

44 Cf. H. Arendt, "Sócrates", op.cit., pp. 45-46.

45 H. Arendt, Entre el pasado y el futuro, op.cit., p. 173.

46 Ibidem, p. 172.

47 Ibidem.

$48 \quad$ Ibidem, p. 173. en relación con un contexto político que amenaza la supervivencia del filósofo, poniendo en peligro la filosofía misma, cuya experiencia solitaria e incomunicable se distingue por su alteridad a los discursos, las doxai, que forman el tejido de las relaciones sociales y políticas.

Para entender adecuadamente estas reflexiones debemos enmarcarlas a partir de una lectura política del pensamiento de Platón que se origina en el entorno de la filología alemana de comienzos del siglo $\mathrm{XX}^{49}$. Este enfoque, que centra la atención en la relevancia política de los escritos del filósofo ateniense, comprende la obra de Karl Popper, La sociedad abierta y sus enemigos, de $1944^{50}$. La interpretación de Popper, que aborda el proyecto de la República platónica como un antecedente de los regímenes totalitarios, marca un antes y un después en las interpretaciones contemporáneas del pensamiento de Platón ${ }^{51}$. La lectura arendtiana, sin embargo, se distancia de la de Popper en la medida en que para ella no se trata de establecer un vínculo directo entre Platón y los totalitarismos. Para Arendt, el vínculo indirecto, que puede rastrearse cruzando la historia de la metafísica con la historia de la política, tiene que ver con la creación de una ontología abstracta, basada en entes ficticios, genéricos y universales, que impiden pensar la política a partir de los elementos concretos, fácticos y plurales que la constituyen ${ }^{52}$. En Platón no encontramos para Arendt un primer intento de formular un Estado totalitario, sino el germen de una relación jerárquica entre teoría y política que tendrá consecuencias duraderas a lo largo de la tradición. Si bien esta lectura tiene el mérito de subrayar la relevancia política de la empresa platónica, en un sentido que se aleja de las imputaciones popperianas, se alimenta asimismo de un exceso hermenéutico basado en una escasa atención a las evidencias textuales, en la sospecha hacia la naturaleza utópica del texto y en una crítica radical de la relación entre metafísica y política ${ }^{53}$.

De esta forma, Arendt está en condiciones de destacar cómo la tentativa platónica de fundamentar la autoridad en el dominio de las Ideas instala en el centro de la política el tema del mando y del dominio, produciendo una separación entre gobernados y gobernantes basada en la obediencia y estableciendo como fuente del poder una dimensión exterior y trascendente de la política mis$\mathrm{ma}^{54}$. Esta tradición de pensamiento se mantiene intacta, como hemos visto, hasta Marx, de modo que la inversión

\footnotetext{
49 Para una reconstrucción crítica del origen y desarrollo de esta lectura de los diálogos platónicos, cf. M. Bonazzi y R. Chiaradonna, "Quale Platone per la política?”, Lo Sguardo. Rivista di Filosofia 27, 2018, pp. 13-28.

50 K. R. Popper, La sociedad abierta y sus enemigos, Barcelona, Paidós, 1991.

51 Para un análisis detenido de esta cuestión, cf.: M. Vegetti, "Un paradigma in cielo”. Platone político da Aristotele al Novecento, Roma, Carocci, 2009, pp. 109-119. Para una crítica de la lectura de Popper, cf. C. Aruzza, "Cleaning the City: Plato and Popper on Political Change", Polis 2, 2012, pp. 259-285 y M. Lane, "Plato, Popper, Strauss and Utopianism: Open Secrets?", History of Philosophy Quarterly 2, 1999, pp. 119-142.

52 Cf. A. Cavarero, "Il Socrate di Hannah Arendt", en H. Arendt, Socrate, Milano, Rafaello Cortina Editore, pp. 73-98, aquí pp. 79-80.

53 Cf. C. Arruzza, "Review Article: "Un paradigma in cielo». Platone politico da Aristotele al Novecento", Historical Materialism 1, 2013, pp. 185-195, aquí p. 190.

54 Cf. E. Tassin, "Pouvoir, autorité et violence. La critique arendtienne de la domination", en J.-C. Goddard, Le pouvoir, Paris, Vrin, 1994, pp. 266-301, aquí p. 276.
} 
que éste opera entre praxis y teoría sería, según Arendt, una prueba más de su supervivencia: "las operaciones rotatorias con las que termina la tradición dan a luz el comienzo en un doble sentido. La aseveración misma de uno de los opuestos [...] necesariamente trae a la luz al opuesto repudiado y demuestra que ambos tienen significado e importancia sólo dentro de esa oposición" 55 . Si las inversiones manifiestan la vigencia del enfoque platónico, la única forma, para Arendt, de salir de la configuración histórica y conceptual de la tradición es oponerle "otra tradición". En el texto Sobre la violencia, después de uniformar la tradición occidental basándose en la común aceptación de la equiparación del poder a una técnica de gobierno, Arendt por esta razón apela a:

otra tradición y otro vocabulario, no menos antiguos y no menos acreditados por el tiempo. Cuando la CiudadEstado ateniense llamó a su constitución una isonomía o cuando los romanos hablaban de la civitas como de su forma de gobierno, pensaban en un concepto del poder y de la ley cuya esencia no se basaba en la relación mandoobediencia ${ }^{56}$.

\section{El tesoro perdido}

La comprensión arendtiana de la polis clásica proporciona una clave de lectura para aclarar no solo el contexto teórico del cual surge su idea de poder sino también la concepción alternativa de la política que ésta vehicula. La centralidad del análisis del pensamiento de Platón en la obra de Arendt es, a su vez, fundamental para entender el desarrollo de la reflexión de la autora. Según Arendt, Platón elabora sus teorías en oposición consciente a la vida política de la ciudad-Estado griega. El filósofo reacciona no solamente a la condena de su maestro, sino a la condición más general de crisis y decadencia de la vida política ateniense. De ahí deriva la necesidad de buscar unos criterios absolutos de los que puedan desprenderse unas normas incuestionables que regulen la vida en común: "La persuasión, peithein, la forma en que los ciudadanos manejaban entre ellos sus asuntos públicos, era para Platón un desafortunado sustituto del tipo de inquebrantable convicción que únicamente podía brotar de la percepción directa de la verdad"57. En el intento de superar las limitaciones de la persuasión, Platón dejó de interesarse por completo en la libertad: "la persuasión se convirtió para él en una forma no de libertad sino de compulsión arbitraria a través de palabras, y en su filosofía política propuso sustituir esta compulsión arbitraria por la coerción de la verdad"58. Queriendo evitar la ruina última de la polis, Platón propuso regir la política al modo de un tirano. Sin embargo, lo relevante de la lectura de Platón no se halla solamente, para Arendt, en la posibilidad de discernir los límites de la tradición filosófico-política a la que este da comienzo,

\footnotetext{
H. Arendt, Entre el pasado y el futuro, op.cit., p. 59.

56 H. Arendt, Sobre la violencia, op.cit., p. 55.

57 H. Arendt, Karl Marx y la tradición del pensamiento político occidental, op. cit., p. 40

$58 \quad$ Ibidem, p. 41.
}

sino también en otras dos direcciones teóricas que de ahí se desprenden. Por un lado, el interés de la figura de Sócrates, que Arendt separa conscientemente de la de su discípulo, y que conduciría a otro tipo de relación, no autoritaria, entre pensamiento y política; por otro, su capacidad de devolvernos, por contraste, una imagen más nítida de una diferente concepción de la política ${ }^{59}$.

En este sentido, el interés del análisis arendtiano se encuentra en el gesto teórico de recomponer los fragmentos de otra tradición, esta sí, en condiciones de oponerse al nihilismo y la autodestrucción en la que termina aquella que había sido dominante. Si bien las tendencias historiográficas más recientes han revisado la centralidad del mundo griego en el pensamiento de Arendt, otorgando relevancia también a sus análisis de las fuentes pertenecientes al mundo romano ${ }^{60}$, este sigue siendo clave a la hora de entender el esfuerzo propositivo e imaginativo llevado a cabo por la autora. En concreto, Arendt utiliza el paradigma de la polis para elucidar lo que hay que considerar como el núcleo de la vida política, es decir, las nociones de pluralidad, acción, poder y libertad pública ${ }^{61}$. Estas últimas, si se consideran a partir de la crítica que la autora desarrolla de las categorías políticas modernas, pueden ser interpretadas como una serie de constelaciones conceptuales alternativas respecto a las elaboraciones modernas: la pluralidad responde a la tensión hacia la unidad; el poder al orden violento de la soberanía; la acción y la libertad presiden la valorización del actuar en conjunto frente a la despolitización de la vida en común. Por lo tanto, Arendt pensaría la política a partir del fin de la tradición moderna, intentando superar los límites impuestos por el predominio del Estado y de sus derivaciones teóricas ${ }^{62}$.

Permaneciendo en el presente, es posible, de este modo, volver al pasado, extrapolando de ello experiencias cuyo sentido, ocultado por la tradición, se puede reconstruir a partir de una contingencia radical, sin tener por ello que establecer una narración histórica lineal y consecuente. Frente a la temporalidad que entiende la historia como proceso, Arendt rehabilita la espacialidad de la experiencia en su concreción contin-

\footnotetext{
9 Cf. sobre este tema F. Birulés, Una herencia sin testamento: Hannah Arendt, Barcelona, Herder, 2007, pp. 66-74. Acerca del Sócrates de Arendt, cf.: M. Canovan, "Socrates or Heidegger? Hannah Arendt's Reflections on Philosophy and Politics", op.cit.; A. Cavarero, "Il Socrate di Hannah Arendt", op.cit.; S. Forti, "Letture socratiche. Arendt, Foucault, Patočka", en H. Arendt, Socrate, Milano, Raffaello Cortina Editore, pp. 99-123. D. Villa, Politics, Philosophy, Terror: Essays on the Thought of Hannah Arendt, Princeton, Princeton University Press, 1999.

60 Cf. M. Leonard, "Arendt and the Ancients: Preface", Classical Philology 113, 2018, pp. 1-5. El número monográfico de la revista está dedicado al análisis de la diversidad de las fuentes que relacionan Arendt con el mundo antiguo. Acerca de este tema, cf. también E. Straehle, "Hannah Arendt y los griegos: apuntes acerca de un malentendido", Logos. Anales del Seminario de Metafísica 51, 2018, pp. 81-98.

${ }_{61}$ Cf. R. Bernstein, op. cit., pp. 82-83 y M. Leonard, "Arendt's Revolutionary Antiquity”, Classical Philology 113, 2018, pp. 53-66, aquí p. 55.

62 Cf. C. Galli, "Hannah Arendt e le categorie politiche della modernità", en R. Esposito (ed.), La pluralità irrapresentabile. Il pensiero politico di Hannah Arendt, Urbino, QuattroVenti, 1987, pp. 15-28, aquí pp. 22-26.
} 
gente $^{63}$. Ese fragmento del pasado que es la polis proyecta una imagen del lugar donde se refleja la idea de política defendida por Arendt, porque lo político no es necesario, como pretende la tradición moderna, y no ha existido siempre y por doquier. Según la pensadora, la política no es un destino del hombre, algo que se pueda dar por supuesto, no es una necesidad ineludible, ya que ella empieza solamente allí donde acaba el reino de las necesidades materiales y de la violencia física y surge únicamente donde los hombres, reconociéndose entre sí, se relacionan entre iguales.

desde el punto de vista histórico, solamente unas pocas grandes épocas lo han conocido y hecho realidad. Sin embargo, estos pocos grandes casos afortunados de la historia son decisivos; únicamente en ellos se pone de manifiesto el sentido de la política, tanto en lo que ésta tiene de salvación como de desgracia. Por este motivo son modélicos, no porque puedan copiarse sino porque ciertas ideas y conceptos que durante un breve periodo fueron plena realidad son determinadas también para las épocas en las que una plena experiencia de lo político es negada ${ }^{64}$.

Sin pretensiones filológicas, y basándose esencialmente en la lectura de los textos poéticos, historiográficos y filosóficos de la cultura griega, Arendt restituye la imagen de la Atenas clásica, como la de una ciudad cuyo espacio está delineado respecto a la centralidad urbanística e ideológica del agora, la cual se encuentra en tensión con el espacio privado del oikos. Esta imagen de la Atenas de Pericles puede seguramente ser criticada por su excesiva simplificación y por la escasa atención a las prácticas institucionales efectivas llevadas a cabo en aquel contexto; por ello, hay que tener en cuenta que la lectura arendtiana se basa esencialmente en un intento de reconstrucción conceptual: el "tesoro" que Arendt busca en la polis es aquella experiencia en la cual no había distinción entre gobernantes y gobernados, en la que el espacio horizontal de la política no había sido dividido por el corte vertical del dominio y donde los hombres se encargaban de los asuntos públicos a partir del razonamiento y de la persuasión:

Ser político, vivir en una polis, significaba que todo se decía por medio de palabras y de persuasión, y no con la fuerza y la violencia. Para el modo de pensar griego, obligar a las personas por medio de la violencia, mandar en vez de persuadir, eran formas pre-políticas para tratar con la gente cuya existencia estaba al margen de la polis, del hogar y de la vida familiar, con ese tipo de gente en que el cabeza de familia gobernaba con poderes despóticos e indisputados, o bien con los bárbaros de Asia, cuyo despotismo era a menudo señalado como semejante a la organización de la familia ${ }^{65}$.
Por ello, cualquiera que se quedase fuera de los confines geográficos y políticos de la polis -esclavo o bárbaro- se definía como aneu logou, "desprovisto, claro está, no de la facultad de discurso, sino de una forma de vida en la que el discurso y sólo éste tenía sentido y donde la preocupación primera de los ciudadanos era hablar entre ellos”66. La polis, por tanto, ofrece la oportunidad de pensar la política como espacio de aparición de la libertad, donde el poder se genera a partir de una dinámica relacional horizontal. Frente al control de las necesidades de la vida, a la economía, al gobierno, al dominio, al poder desigual, a la esclavitud, y a la desigualdad que, según Arendt, pertenecen todas ellas a la esfera privada, y a un ámbito pre-político, la vida de la polis se configuraba como una modalidad fenoménica de aparición de los hombres unos frente a otros:

En esta conversación incesante, los griegos descubrieron que nuestro mundo común se ve siempre desde un número infinito de posiciones diferentes, a las que corresponden los más diversos puntos de vista. En un flujo de argumentos totalmente inagotable, como los que presentaban los sofistas a los atenienses, el ciudadano griego aprendió a intercambiar sus propios puntos de vista, su propia "opinión" -la forma en que el mundo se le aparecía y mostraba (dokei moi, "me parece", de donde proviene doxa, "opinión")- con los de sus conciudadanos. Los griegos aprendieron a comprender, no a comprenderse como individuos sino a mirar al mismo mundo desde la posición del otro, a ver lo mismo bajo aspectos muy distintos y, a menudo, opuestos $^{67}$.

La racionalización moderna de la política que convierte a esta última en una técnica de administración del gobierno representa en realidad, para Arendt, una expropiación de la política: invadido por las actividades propias de la esfera privada el espacio público deja de existir en cuanto espacio de aparición y terreno de confrontación, donde los hombres pueden, manifestándose unos a los otros en la pluralidad de sus perspectivas diferentes, apoderarse de un mundo común. Pero este mundo común se produce sólo manteniendo abierta la pluralidad de las perspectivas, lo que es posible cuando los hombres se relacionan entre ellos como homoioi, fuera de las relaciones de neutralización y dominio. La democracia ateniense, con su modalidad política relacional, revela para Arendt la importancia de crear las condiciones no solamente para el mantenimiento de una esfera política autónoma de la esfera social, sino que apunta a la necesidad de pensar una y otra vez las frágiles condiciones de una política auténticamente democrática.

\footnotetext{
63 Cf. L. Bazzicalupo, Hannah Arendt. La storia per la poltica, op.cit., pp. 20-23.

${ }^{64}$ H. Arendt, ¿Qué es política?, op.cit., p. 71.

${ }_{65}$ H. Arendt, La condición humana, op.cit., p. 40.
}

\footnotetext{
Ibidem, p. 41.

${ }_{67}$ H. Arendt, Entre el pasado y el futuro, op.cit., p. 84.
} 


\section{Bibliografía}

Abensour, M., “Against the Sovereignity of Philosophy over Politcs: Arendt's Reading of Plato’s Cave Allegory”, Social Research 74, 2007, pp. 985-992.

Álvarez Yágüez, J., "Polis y política: M. Heidegger y H. Arendt”, Res Publica 22, 2019, pp. 195-215.

Arruzza, C., "Cleaning the City: Plato and Popper on Political Change", Polis 2, 2012, pp. 259-285.

Arruzza, C., "Review Article of M. Vegettti «Un paradigma in cielo». Platone politico da Aristotele al Novecento", Historical Materialism 1, 2013, pp. 185-195.

Arendt, H., Karl Marx and the Tradition of Western Political Thought, long draft, 1953, Washington, Library of Congress, Manuscripts Division, "The papers of Hannah Arendt", box 64: https://memory.loc.gov/ammem/arendthtml/arendthome. $\underline{\mathrm{html}}$.

-, ¿Qué es la política?, Barcelona, Paidós, 1997.

-, La condición humana, Barcelona, Paidós, 1998.

-, "Karl Marx and the Tradition of Western Political Thought", Social Research 69, 2002, pp. 273-289.

-, Entre el pasado y el futuro. Ocho ejercicios sobre la reflexión política, Barcelona, Península, 2003.

-, Sobre la revolución, Madrid, Alianza, 2004.

-, Sobre la violencia, Madrid, Alianza, 2006.

-, Los orígenes del totalitarismo, Madrid, Alianza, 2006.

-, Karl Marx y la tradición del pensamiento político occidental, Madrid, Encuentro, 2007.

-, “Sócrates", en H. Arendt, La promesa de la política, Barcelona, Paidós, 2008, pp. 43-45.

Basili, C., "Los límites de la política. Hannah Arendt sobre la polís clásica” en Alviz Fernández, M. y Hernández de la Fuente, D., De horos a limes: el concepto de frontera en el mundo antiguo y su recepción, Madrid, Escolar y Mayo Editores, 2017, pp. 241-252.

Bazzicalupo, L., Hannah Arendt: la storia per la politica, Napoli, Edizioni Scientifiche Italiane, 1996.

Bernstein, R., Violence. Thinking without banisters, Malden, Polity Press, 2013.

Birulés, F., “Introducción. ¿Por qué debe haber alguien y no nadie?”, en H. Arendt, ¿Qué es política?, Barcelona, Paídos, 1997.

-, Una herencia sin testamento: Hannah Arendt, Barcelona, Herder, 2007.

Bonazzi, M. y Chiaradonna, R., “Quale Platone per la política?”, Lo Sguardo. Rivista di Filosofia 27, 2018, pp. 13-28.

Brunkhorst, H., "The Productivity of Power: Hannah Arendt's Renewal of the Classical Concepts of Politics", Revista de ciencia politica 2, 2006, pp.125-136.

Cambiano, G., Il ritorno degli antichi, Roma-Bari, Laterza, 1988.

Canovan, M., "Socrates or Heidegger? Hannah Arendt's Reflections on Philosophy and Politics", Social Research 1, 1990, pp. 135-165.

Cassin, B., “Grecs et Romains: les paradigmes de l'antiquité chez Arendt et Heidegger”, en Abensour, M. (ed.), Ontologie et politique: Actes du Colloque Hannah Arendt, Paris, Tierce, pp. 17-39.

Cavarero, A., "Note arendtiane sulla caverna di Platone", en Forti, S., Hannah Arendt, Milano, Bruno Mondadori Editore, 1991, pp. 205-225.

-, "Politicinzg theory", en Political Theory, 4, 2002, pp. 506-532.

-, Il femminile negato. La radice greca della violenza occidentale, Villa Verucchio, Pazzini Editore, 2007,

-, "Il Socrate di Hannah Arendt", en H. Arendt, Socrate, Milano, Raffaello Cortina Editore, 2015, pp. 73-98.

Dal Lago, A., "La città perduta", en H. Arendt, Vita activa. La condizione umana, Milano, Bompiani, pp. VII-XXXIII, 2006.

Duso, G., Il potere: per la storia della filosofia politica moderna, Roma, Carocci, 1999.

Enegrén, A., La pensée politique de Hannah Arendt, Paris, Presses Universitaires de France, 1984.

Esposito, R., "Politica e tradizione. Ad Hannah Arendt", Il Centauro 13-14, 1985, pp. 97-136.

-, El origen de la politica. ¿Hannah Arendt o Simone Weil?, Barcelona, Paidós, 1999.

-, Diez pensamientos acerca de la política, Buenos Aires, Fondo de Cultura Económica, 2012.

Fanon, F., Los condenados de la tierra, Tafalla, Txalaparta, 2011.

Forti, S., Vida del espíritu y tiempo de la polis. Hannah Arendt entre filosofía y política, Madrid, Cátedra, 2001.

-, Totalitarismo. Trayectoria de una idea límite, Barcelona, Herder Editorial, 2008.

-, "Letture socratiche. Arendt, Foucault, Patočka", en Arendt, H., Socrate, Milano, Raffaello Cortina Editore, 2015, pp. 99-123.

Galli, C., "Hannah Arendt e le categorie politiche della modernità", en Esposito, R. (ed.), La pluralità irrapresentabile. Il pensiero politico di Hannah Arendt, Urbino, QuattroVenti, 1987, pp. 15-28.

Guaraldo, O., "Postcritica: una genealogia", en Politica\&Società 2, 2018, pp. 163-190.

Habermas, J., "Hannah Arendt's Communications Concept of Power", Social Research 44, 1977, pp. 3-24.

Lane, M., "Plato, Popper, Strauss and Utopianism: Open Secrets?", History of Philosophy Quarterly 2, 1999, pp. 119-142.

Lefort, C., "Hannah Arendt and the Question of the Political", en Lefort, C., Democracy and Political Theory, Minneapolis, University of Minnesota Press, 1988, pp. 45-55.

Leonard, M., "Arendt and the Ancients: Preface", Classical Philology 113, 2018, pp. 1-5.

-, “Arendt's Revolutionary Antiquity", Classical Philology 113, 2018, pp. 53-66.

Popper, K. R., La sociedad abierta y sus enemigos, Barcelona, Paidós, 1991.

Prior Olmos, Á., "El debate sobre la violencia: Arendt y Fanon”, en Villacañas Berlanga, J.L. y Ruiz Sanjuán, C. (eds.), Populismo versus Republicanismo. Genealogía, historia, crítica, Madrid, Biblioteca Nueva, pp. 131-150.

Ricoeur, P., "Pouvoir et violence", en Abensour, M. (ed.), Ontologie et politique: Actes du Colloque Hannah Arendt, Paris, Tierce, 1989, pp. 141-159.

Straehle, E., "Hannah Arendt y los griegos: apuntes acerca de un malentendido", Logos. Anales del Seminario de Metafisica 51, 2018, pp. 81-98.

Taminiaux, J., “Arendt, disciple de Heidegger?”, Etudes phénoménologiques 2, 1985, pp. 111-136. 
Tassin E., "Pouvoir, autorité et violence. La critique arendtienne de la domination", en J.-C. Goddard, Le pouvoir, Paris, Vrin, 1994, pp. 266-301.

Vegetti M., Los origines de la racionalidad cientifica: el escalpelo y la pluma, Barcelona, Península, 1981.

-, “Un paradigma in cielo". Platone político da Aristotele al Novecento, Roma, Carocci, 2009, pp. 109-119.

Villa D., Politics, Philosophy, Terror: Essays on the Thought of Hannah Arendt, Princeton, Princeton University Press, 1999. 